\title{
Flexible Manufacturing Technology for Children's Customized Furniture
}

\author{
Linqi Zhao, Xianqing Xiong*, Shuman Zhu, Yuyu Wu, Mengnan Yu and Yu Di \\ ${ }^{1}$ College of Furniture and Industrial Design, Nanjing Forestry University, Nanjing 210037, China \\ *Corresponding author
}

\begin{abstract}
Aiming at the design defects and quality problems in Children's Furniture, flexible manufacturing of children's furniture is proposed. It is by flexible design, flexible production and information management that flexible manufacturing can overcome the impact of the function, style, quality requirement in children 's furniture for the production can be, reduce product costs, short developing time, help enterprises to quickly respond to market, produce furniture truly suitable for children, and build a good growing environment for children.
\end{abstract}

\section{Keywords-children's furniture; flexible manufacture; technology}

Along with the rapid ascension of the national economic level, Chinese furniture industry is growing stronger. Children's furniture develops rapidly as an independent kind of furniture, which has occupied $9 \%$ 10\% of the entire market in only ten years' time[1].

Although children's furniture market has developed as a certain scale, as a whole it is also at a low-end market level[2]. The development is suffering bottleneck in recent, and design flaws and quality issues are common in products. It is hard to obtain right children's furniture for consumers, so that the cost of production for the company rises gradually.

Based on this, the article will apply flexible manufacturing to furniture, put the children's furniture of a domestic enterprise into flexible manufacturing practice through its key technology, in order to solve their problems encountered in production, which is of great significance for the enterprises to implement flexible production.

\section{The NeCEssity OF CHILDREN 'S FURNITURE FLEXIBLE MANUFACTURING}

\section{A. Production Problems of Children's Furniture}

Unreasonable structure and design, low quality and accurace are common in children's furniture on the market, and the fundamental reason for this is the difference of children 's furniture and adult furniture. Due to the particularity of children's physical and psychological,the requirement for appearance, structure, function, performance, cycle are typically higher than adult furniture, which put great strains on production, the main performance are as follow:

1) High proportion of abnormity parts: Children prefer furniture that is changeable and slick.This is not just for security reasons, it also has certain help to children's creativity and imagination;

2) Various kinds of sizes: Children's body grow up fast in the short term, which causes the much higher requirement for furniture size than adult furniture;

3) High requirements of quality and precision: relevant state standards expressly to chamfer, pore, elasticity, and stability[3];

4) Rapid replacement cycle: Whether outward appearance or furniture size would change with rapid change of children's physical and psychological.

These characteristics and the relevant provisions put forward higher requirements for the children's furniture, but also increase its design $\mathrm{R} \& \mathrm{D}$ and production costs. Diversified market demand and rapid replacement cycle require the production capacity Children's furniture enterprises with rapid response to market.

\section{B. The Necessity of Flexible Manufacturing for Children's Furniture}

Children's furniture is important to children's growth, and right children's furniture is a great help to skeleton development and intellectual development. Many designers design furniture specifically for children according to their characteristics, but the constraints of production capacity and manufacturing cost result its too high price to be massly producted. It's difficult to be consumed by the average family, but mass production of furniture has certain flaw.

Faced with this, flexible manufacturing could be a potent weapon. Embodied in:

1) Improving process capacity for abnormity parts and various sizes. Machining of Complex Parts like abnormity parts and various sizes can be achieved in flexible manufacturing technology[4];

2) Solve the problem of quality and precision. Set up production modules based on process similarity, which would help workers to master processing skills, so as to enhance the quality and accuracy of furniture;

3) Modular production saves processing and logistics time, shorten the production cycle;

4) Flexible and adjustable production plan. The flexible manufacturing system can analyze the dynamic environment, appropriately deploy resources with basic facilities[5], optimize the schedules that have been generated, and rapidly response to market changes. 
Children's furniture in the design, production and sales of all sectors has gained all-round development. It has the basic conditions of flexible manufacturing, but the lack of a more complete system structure as a guide, which leads to the mutual constraints among design, production, and sales. And the information can not be delivered quickly and efficiently so that the resource can not be configured properly.

\section{FleXIBLE MANUFACTURING TECHNOLOGY FOR CHILDREN'S FURNITURE}

\section{A. General Framework}

Flexible manufacturing of children's furniture based on that flexible manufacturing theory control children's furniture life cycle of all aspects: From the beginning of product development and design, modular design and parts standardization have been implemented through flexible design, build products family and Parameterized model library; at the production stage, make flexible scheduling of production through flexible planning, set up production modules according to similar processing principle, Parts within the same module have similar technique and same process, Reduce tool change, equipment adjustment, preparation time. The entire production process is regulated through the means of information, and the substance of the program links up the various operation flows like designing, planning, production and management. Flexible thinking should be used throughout the life cycle of children's furniture, in order to realize the enterprise flexible strategy. The overall architecture is shown in Figure I

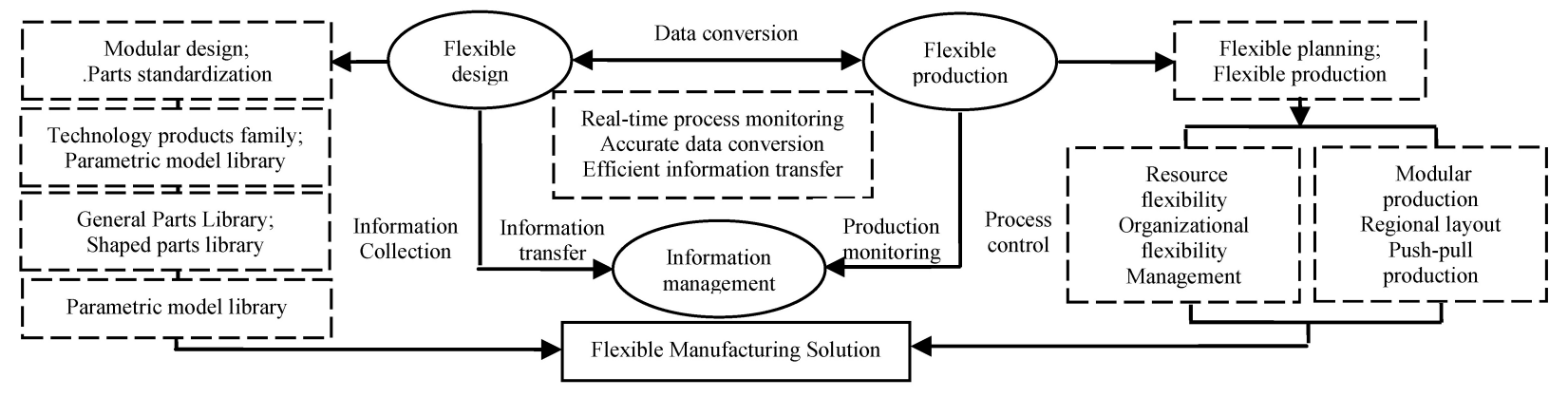

FIGURE I. CHILDREN'S FURNITURE FLEXIBLE MANUFACTURING

In this paper, making flexible manufacturing practice by using company A as an example, the children's furniture in this enterprise is American-style bedroom series, including four types of furniture: bed, cabinet, table and chair. Production model is the traditional assembly line type, which is suitable for mass production. When the orders have many styles with a small number, the workshop is facing the problem of frequently transfering machine and changing tools.Logistics operation confusion, which results in the extension of the production cycle and the increasing cost. New product development cycle is longer than this production mode, it averaged only four new product every year. Customer orders principally are old funds and workers rely on experience, so enterprises can not respond quickly to the market. Based on this, the paper propose flexible reforming from aspects of design, production, management.

\section{B. Flexible Design}

Flexible design is the basis of flexible manufacturing of children's furniture. Furniture production process should be flexible and changeable under multi-species small batch production mode, which requires that the design and production of data can be docked as well as the rapid conversion between design and material BOM.

The traditional way is the communication between design and production personnel, and the result of communication is a compromise between both sides. The flexibility of the design emphasizes that the standardization of the components can be thougt carefully at the beginning of the design, setting up parts technology products family, at the same time setting up the parametric model library for children furniture products. With the accumulation of design, product family and model library continues to expand, which not only helps designers to quickly design for the needs of children, but also helps companies to quickly make adjustment and optimization to the design.

\section{1) Key technologies}

a.Parts technology products family: The purpose of dividing the product family is to make the standardization of Children's furniture structure, improve component repetition rate, reduce the production pressure caused by excessive of shaped parts. Noticing that the product family should include common and odd-shaped components, allow the push and pull with the production mode in the late production [6].

$b$, Parametric model library of components:After the product family is established[7], the components within the product family should be encoded; coding includes product series, structural characteristics, process operations, delivery and other information, set up the standardized system. With the continuous accumulation of design, parametric model library is formed, as shown in Figure II. Designers could directly retrieve mature module parts from the module library in the follow-up development, the process data can also be automatically generated from the model library.

\section{2) Practical research}

Implemented a flexible transformation for enterprise A, first split the furniture parts: bed, bedside tables, tables and chairs to break the affiliation. The key technologies should be divided according to product family 2.2, and the product family should be re-divide according to the structure and process similarity, so that it can be divided into the following six categories.

a, Strip: Generally with no complex structure, with regular cuboid shape, the processing flow is relatively simple.Mainly contains: Bars, support foot, edge band, connecting plate, 
triangular wood, rail strips, reinforcement, cross and other structural components.

b, Cylinder: Needing two Impositions, the main processing equipment is woodworking lathe.Mainly contains: Legs, pillars, tables / chairs Leg stool Rotary parts

c, Curve: The overall shape is a curved line; the main processing equipment is sawing machines.Mainly contains: Bed top line, panel, cabinet feet, chair brain, chair legs, cushion plate, table board, and table legs and so on. d, Line: The overall shape is a straight line, generally surrounded by plane processing molding.Mainly contains: Bed / cabinet / table / chair legs, pad, feet box, column.

e, Drawer: The production of draw-box components, the main processing equipment is cutting machine.Mainly contains: Keyboard, front / side of the keyboard, the keyboard, end / face / side / rear plate, etc.

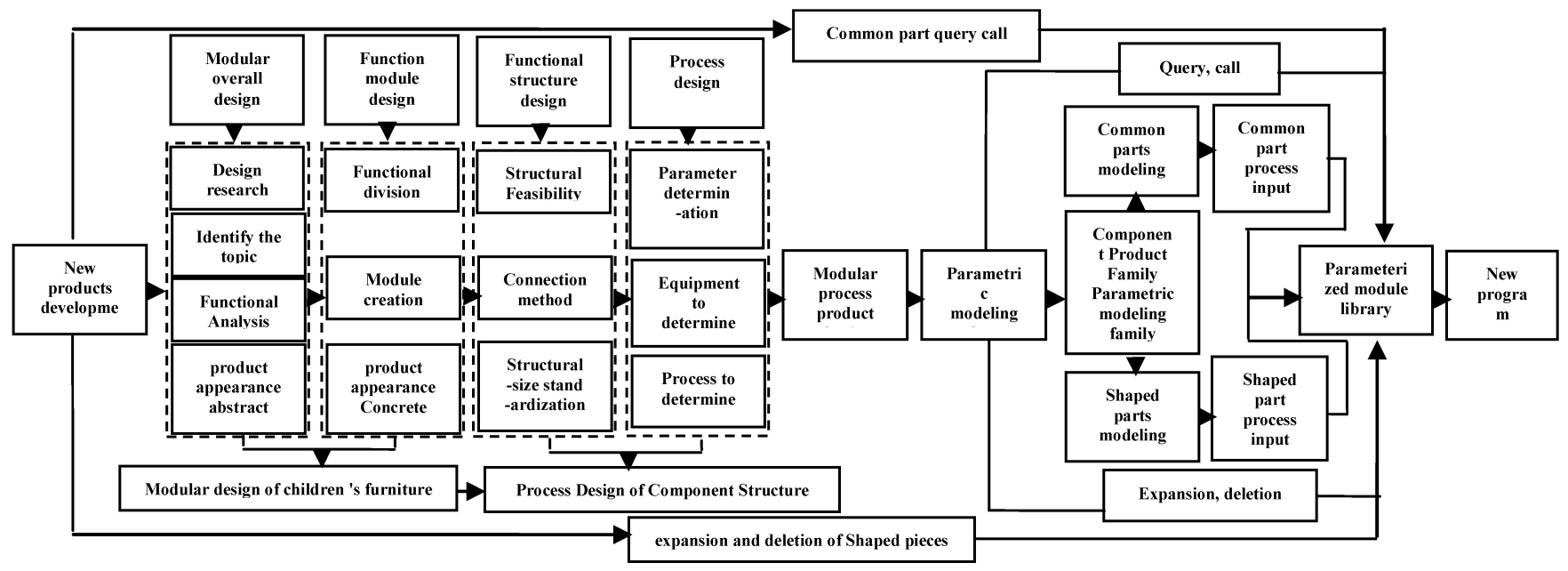

FIGURE II. FLEXIBLE DESIGN PROGRAM OF CHILDREN'S FURNITURE

f, Sheet-metal: All the preparation process for wood - based panel parts.Mainly contains: Bed substrate, belly board, stickers, face / side / bottom / back plate, pad and so on.

Internal parts of product family have similar structures, process is basically the same, follow-up program can be extension on the basis of the serialization and standardization, which is conducive to the design program convert to the material BOM, greatly reducing the design development cycle, solve the problem of furniture replacement caused by children growing up, adapt to the individual needs of different children, which contributes to its intellectual development.

\section{Flexible Production}

\section{1) Key technologies}

a, Flexible production plan:After the customer orders, furniture companies need to make the appropriate plan according to lead times and enterprise resources, concrete implement process will make adjustments caused by the supply of materials, workshop production, delivery and other conditions change, which require that all aspects of the program are involved in coordination [8]. The purpose of flexible production planning is making flexible strategic plan for the resources, organization, planning, and management through flexible strategic thinking. Resource procurement and distribution should be flexible to do a good job of coordinating the first-in, first-out and the first-out; it has decentralized the various departments, improve management ability and communication efficiency; Production problems can be timely controled, and the relationship between production and planning can be coordinated.
b,Flexible machining: Flexible machining is the core of the entire program, and flexible production planning needs to rely on flexible machining to achieve. 1Basic process: accords to the parts craft parts family to establish the corresponding production module, design for the production process of each module, through the workshop of the processing capacity to determine the type and quantity of equipment, which accordingly have the equipment within the module layout, finally, the overall layout and logistics planning .

The establishment of production modules. The process standards and quality requirements of children's furniture are more stringent relative to the general furniture, Flexible production put the components with similar structure and process into a same production module .The workers within the module can master the processing of such components and techniques due to long-term working, which helps to improve the accuracy and quality of children's furniture, save the time of adjusting, tool change, mold preparation and logistics operation. Noting that this production module should meet the group technology concept and requirements, in order to improve production efficiency for the purpose.

Module within the layout. The layout of the equipment has a straight line layout and block layout . Linear layout is more efficient in high-volume production tasks, yet without flexibility.Once the process sequence has changed, the entire layout needs to be re-planned. The stability of regional layout is higher, when the process or task changes. Local production lines can be achieved within the region at the shortest logistics distance, so the module equipment generally use regional layout. 
Push-pull Mixed production.At the beginning of developing the production plan, divide the children's furniture parts family into standardized universal parts and diversified shaped parts. Take the "push type production" for common parts, advance production according to the forecast, and do a certain safety stock, to achieve the scale of mass production benefits and reduce costs; Take "pull production" for shaped parts to shorten its production cycle, and shorten the delivery of personalized children's furniture. Based on the bulk of the general parts and variety of shaped parts, combine the "push" and "pull", to solve the contradiction between mass production and individual demand.

\section{2) Practical research}

According to processing similarity, put out planning and design for process and equipment within the family on the basis of family 2.2, and create a production module as shown in Table I :

All parts must be prepared, in order to increase solid wood and sheet material preparation module on the basis of product

family. Components of these modules have similar structure ,the same process, and a regional layout of the internal equipment, and using push-pull combined production, to achieve the module within the mass production.When production tasks change, flexiblility enables the production module to achieve flexible production.

\section{TABLE I. WORKING PROCEDURE OF PRODUCTION MODULE}

\begin{tabular}{|c|c|}
\hline $\begin{array}{l}\text { Production } \\
\text { module }\end{array}$ & Process and equipment \\
\hline $\begin{array}{l}\text { Solid wood } \\
\text { preparation } \\
\text { module }\end{array}$ & $\begin{array}{l}\text { Fragmentation (computer multi-chip saw) } \rightarrow \text { Preferably fixed } \\
\text { length (preferably saw) } \rightarrow \text { Secondary slice (computer single } \\
\text { multi-chip saw) } \rightarrow \text { The second preferred fixed length (wind shear } \\
\text { saw) } \rightarrow \text { Press planning (double-sided plane) } \rightarrow \text { Flat sand (flat sand } \\
\text { machine) } \rightarrow \text { Puzzle (wheel puzzle machine) }\end{array}$ \\
\hline $\begin{array}{l}\text { Block solid } \\
\text { wood } \\
\text { modules }\end{array}$ & $\begin{array}{l}\text { Double-sided planning } \quad \text { (double-sided plane) } \rightarrow \text { Beveling } \\
\text { Machine } \rightarrow \text { Flat sand (flat sand machine) } \rightarrow \text { Fine cut long (wind } \\
\text { shear saw, double-headed shear) } \rightarrow \text { Drilling (four rows of drills) }\end{array}$ \\
\hline $\begin{array}{l}\text { Rotary } \\
\text { solid wood } \\
\text { module }\end{array}$ & $\begin{array}{l}\text { Four-sided planning } \rightarrow \text { Car-shaped (hand-drawn lines, automatic } \\
\text { lathes) } \rightarrow \text { Sanding (manual lathe, brown sand machine) } \rightarrow \text { Fine } \\
\text { Cut }(\text { Circular Saw) } \rightarrow \text { Fixed length (double-headed shear) }\end{array}$ \\
\hline $\begin{array}{l}\text { Bending } \\
\text { modeling } \\
\text { module }\end{array}$ & $\begin{array}{l}\text { Jig saw (hand-drawn line, band sawing processing) } \rightarrow \text { Press } \\
\text { planning (double-sided plane) } \rightarrow \text { Secondary flat sand (flat sand } \\
\text { machine) } \rightarrow \text { Forming (single } / \text { double vertical shaft) } \rightarrow \text { Precision } \\
\text { cut long (double-headed shear) } \rightarrow \text { Milling end line (single vertical } \\
\text { axis) } \rightarrow \text { Drilling (horizontal drilling) } \rightarrow \text { Sanding (sponge sanding } \\
\text { machine) }\end{array}$ \\
\hline $\begin{array}{l}\text { Linear } \\
\text { modeling } \\
\text { module }\end{array}$ & $\begin{array}{l}\text { Forming press (planning) } \rightarrow \text { Patching (manual) } \rightarrow \text { Flat sand (flat } \\
\text { sand machine) } \rightarrow \text { Precision cut long } \text { (double-headed } \\
\text { shear) } \rightarrow \text { Drilling (four rows of drills) }\end{array}$ \\
\hline $\begin{array}{l}\text { Draw box } \\
\text { module }\end{array}$ & $\begin{array}{l}\text { Cutting board fine cut (push table saw, double-headed } \\
\text { shear) } \rightarrow \text { Open tendon (double-headed sawing machine) } \rightarrow \text { Milling } \\
\text { edge (router milling machine) } \rightarrow \text { Drilling (bench drill) } \rightarrow \text { Slotting } \\
\text { (Router) } \rightarrow \text { Gluing assembly (artificial) } \rightarrow \text { Sanding (artificial) }\end{array}$ \\
\hline
\end{tabular}

\section{Information-Based Management}

Information management is a strong guarantee of flexible manufacturing scheme for children's furniture and the flexible adjustment of the plan must be based on the accurate analysis and judgment of the effective information. Therefore, real-time process monitoring of production and efficient information transfer is required. General production information management structure is as follow:

a, The transmission of production information: Including production tasks and process information, production tasks develop by planning department and production department according to lead time, material in place situation, and workshop production capacity; Process information develop by technology department, the department of design and production according to product solutions and workshop equipment development process .Including CAD drawings, material quota, process flow, machine tool CAM processing technology, technology and equipment parameters, operating methods and acceptance criteria.

b, Information storage and reading: Workers need to store and read process information in the production to guide production, which can be achieved through paper documents, sample templates and digital terminals, etc.

c, Real-time collection of plant data: Including production schedule, equipment type, running speed, running time, operating efficiency, operating personnel, etc.

d,Production control: Production and planning department analyze the production process according to market order requirements and information of workshop collection, including changes in the number of orders, process changes, priority scheduling, early and late delivery.

e, Workshop feedback: Including LED display to display the production plan, progress and change notification, the mobile terminal forms a paper document by transmitting picture information and voice commands, faxes, printers and other equipment.

Through the production of information management, it can achieve real-time monitoring and adjustment and optimization for the production process data. Through the analysis and judgment of its information, production planning could flexibly command machining, thereby enabling flexible manufacturing.

\section{CONCLUSIONS}

China's children's furniture industry is facing a huge bottleneck; the fundamental reason is that most of the enterprise manufacturing level can not meet the design requirements. The flexible manufacturing technology can be used in children's furniture industry, in order to enhance the level of children's furniture manufacturing through flexible design, flexible production and information management, and meet diversified market demand, reduce production costs and cycle, improve quality, which has a very important significance for the transformation and upgrading of enterprises, and children's health development.

\section{ACKNOWLEDGEMENTS}

A Project of 2016 Jiangsu College students Innovation Training Program (201610298002Z) .A Project Funded by the Priority Academic Program Development of Jiangsu Higher Education Institutions(PAPD). 


\section{REFERENCES}

[1] FAN Weiyong, ZHAO Zhijuan. Dynamics and Development Trend of Furniture for Kids Industry [J]. Journal of Zhejiang Forestry Science and Technology,2011,31(4):70-75.

[2] CHEN Yongchao ,PENG Xiaxia. The Analysis on Children Furniture Industry in China[J]. China Forest Products Industry,2015,42(8):10-12.

[3] GB 28007-2011, General technical requirements for children's furniture [S].

[4] ]M Nurdin,AL Hakim .A Development of Flexible Manufacturing System using POLMAN T-100 Vise Casting Component as a Case Study[J].Procedia Manufacturing, 2015,2:77-81.

[5] I Badr,P Göhner.Incorporating GA-Based Optimization into a MultiAgent Architecture for FMS Scheduling[J].IFAC Proceedings Volumes,2010,43(4):102-107.

[6] ZHAI Lili, WANG Huan, QI Kai, WU Fei. Research on flexible production planning for mass customization [J]. Application Research of Computers, 2012,29(7):2544-2548.

[7] XIONG Xianzing. ZHONG Shilu. WU Zhihui. A Coding Method for Identi 介 ing Solid Wood Furniture Manufacturing Processes[J]. China Wood Industry, 2009,23(6):8-10.

[8] TAO Tao,XIANG Shilong,CHEN Xingyan. Research on flexible production planning management in furniture enterprises[C].Proceedings of International Conference on Engineering and Business Management(EBM2011).

[9] XIONC Xianging,CAI Qi ,WU Zhihui , HUANG Qiongtao.Planning of Large-scale Custom Furniture Production Line and Key Technologies of Workshop Management[J]. China Wood Industry, 2013,40(2):35-38. 